\title{
Synthesis and anticancer activities of polymethylenedioxy analogues of combretastatin A-2
}

\author{
Yun-Seon Kwak', So-Hyun Joo ${ }^{1}$, Enkhtaivan Gansukh², Bhunpendra M. Mistry ${ }^{3}$ and Young Soo Keum ${ }^{*}$
}

\begin{abstract}
Combretastatin A-4 is a highly potent natural stilbene that can inhibit cancer cell proliferation. Numerous analogues of combretastatin A-4 have been proposed for clinical applications. However, structural studies of combretastatin A-2, a methylenedioxy derivative of combretastain A-4, are not available. In this study, various analogues of combretastatin A-2 with polymethylenedioxy spacer were prepared and their antiproliferative activities to four human cancer cell lines (HeLa, SK-OV-3, A549, and HT-29) and two normal cells (HaCaT and MDCK) were evaluated. Binding characteristics were evaluated based on computational docking and previously reported experimental data. Results suggest that their binding conformations are highly dependent on steric volume and electrostatic properties of substituents.
\end{abstract}

Keywords: Polymethylenedioxy, Combretastatin, Computational docking, Antiproliferative activity, Stilbene

\section{Introduction}

Tubulin association is an important biological process targeted by many anti-proliferative agents. Stilbenes are well-established pharmacophores in medicinal chemistry that play an important role in antitumor treatment (Fig. 1a). For example, combretastatin A-2 (CA-2) and combretastatin A-4 (CA-4) from Combretum caffrum are among the most potent antimitotic agents that can disrupt microtubule homeostasis. CA-4 is as an important lead compound for anticancer drug development because of its strong cytotoxicity and simple structure [1-5]. Numerous structural modifications of CA-4 have been made to improve their efficacy based on structure-activity relationships (SARs) [1-8]. Recent SAR studies have shown some essential features of bioactive CA-4 derivatives [2-8]. For example, the cis-olefinic bridge between ring $\mathrm{A}$ and ring $\mathrm{B}$ is strictly required and the 3,4,5-trimethoxy group on ring A and 4-methoxy group on ring $B$ are preferred substituents for strong activity $[1,3,6]$. In addition, 3-hydroxy substitution on ring $B$ usually

\footnotetext{
*Correspondence: rational@konkuk.ac.kr

${ }^{1}$ Department of Crop Science, Konkuk University, 120 Neungdong-ro, Gwangjin-gu, Seoul 05029, Korea

Full list of author information is available at the end of the article
}

enhances the activity. Substituent at this position can be replaced by bromine or fluorine atom without significant loss of activity $[1,6]$. Analogues with naphthyl group also have reasonable efficacy on various tumor cell lines [2]. In addition to stilbenes, analogues with conformationally restricted olefinic bond (e.g., imidazole, oxazole, and pyrazole) have also been prepared [7, 9, 10]. Binding site of CA-4 has been hypothesized to be the colchicine domain of $\beta$-tubulin through displacement studies [6]. A recent structural study has proven such hypothesis [11]. Crystallographic data have provided detailed features of binding sites. For example, CA-4 is more deeply buried in the binding domain than colchicine. The 3,4,5-trimethoxyphenyl unit of CA-4 was moved inward than that of colchicine (approximately 1.22 angstrom) [11]. Molecular dynamic simulation has shown that the superior activity of CA-4 over its trans-isomer may result from stronger interaction between CA-4 and $\beta$-tubulin. Several amino acids can interact with the trimethoxy group of CA-4 mainly through hydrophobic interactions. SAR studies with bulkier analogues (e.g., 3,4,5-triethoxy in ring $\mathrm{A}$ ) have shown lower activity which is indicative of small binding space around ring A [6]. However, some analogues with much smaller substituents (e.g., 3,4,5-trifluoro substituents in ring A) are known to be equally 
a

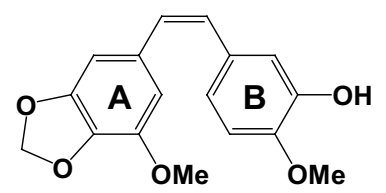

Combretastatin A-2

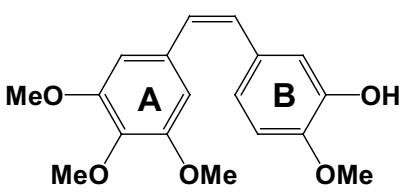

Combretastatin A-4 (1)

b

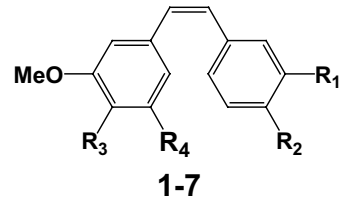

1, $8 \quad R_{1}=\mathrm{OH}, R_{2}=$ OMe, $R_{3}=R_{4}=3,4$-diMeO, Combretastain A4 (1)

$2,9 \quad R_{1}=H, R_{2}=O M e, R_{3}=R_{4}=3,4-d i M e O$

3, $10 \quad R_{1}=H, R_{2}=O C F_{3}, R_{3}=R_{4}=3,4-d i M e O$<smiles>[R2]c1ccc(/C=C/c2cc([R3])c([R])c(OC)c2)cc1[R]</smiles>

4, $11 \quad R_{1}=H, R_{2}=O M e, R_{3}-R_{4}=-O C_{2} \mathrm{O}$ -

$5,12 \mathrm{R}_{1}=\mathrm{H}, \mathrm{R}_{2}=\mathrm{OMe}, \mathrm{R}_{3}-\mathrm{R}_{4}=-\mathrm{OCH}_{2} \mathrm{CH}_{2} \mathrm{O}$ -

6, $13 \quad \mathrm{R}_{1}=\mathrm{H}, \mathrm{R}_{2}=\mathrm{OMe}, \mathrm{R}_{3}-\mathrm{R}_{4}=-\mathrm{OCH}_{2} \mathrm{CH}_{2} \mathrm{CH}_{2} \mathrm{O}$ -

$7,14 R_{1}=\mathrm{H}, \mathrm{R}_{2}=\mathrm{OMe}, \mathrm{R}_{3}-\mathrm{R}_{4}=-\mathrm{OCH}_{2} \mathrm{CH}_{2} \mathrm{CH}_{2} \mathrm{CH}_{2} \mathrm{O}$ -

Fig. 1 Structures of antiproliferative stilbenes from Combretum caffrum and annotations of ring $A$ and $B(\mathbf{a})$ and synthetic stilbenes (b) in this study

potent [6]. These results suggest that steric complementarity alone cannot explain cytotoxicities of CA-4 derivatives. In comparison with CA-4, SARs with CA-2 have been scarcely studied. Semenov et al. [12] have reported that CA-2 analogue with benzodioxin ring is almost equally potent to CA-4 in sea urchin embryo assay. However, there were no additional researches.

In this study, several polymethylenedioxy analogues of CA-2 were prepared and their cytotoxicities to several human cancer cell lines and normal cells were evaluated.

\section{Materials and methods}

\section{Chemical syntheses of stilbenes}

Substituted stilbenes were prepared by Wittig reaction from substituted benzaldehydes and triphenylphosphonium salts of substituted benzyl bromide (TPP salt). In detail, a mixture of TPP salts $(5 \mathrm{mmol})$ and benzaldehydes $(5 \mathrm{mmol})$ in dry DMF $(15 \mathrm{~mL})$ was dropwise added to a suspension of $\mathrm{Kt}$-BuO $(10 \mathrm{mmol})$ in dry DMF $(20 \mathrm{~mL})$ in ice bath. After addition, the mixture was further stirred for $15 \mathrm{~min}$ and heated to $80{ }^{\circ} \mathrm{C}$ for $5-10 \mathrm{~h}$. The cooled mixture was diluted with $5 \%$ brine $(400 \mathrm{~mL})$ and extracted with ether $(400 \mathrm{~mL}$, three times). Combined extracts were washed with $5 \%$ brine (400 mL, 3 times) and dried over anhydrous $\mathrm{Na}_{2} \mathrm{SO}_{4}$. After removal of solvent, the residue was purified by silica gel column chromatography with a mixture of ethyl acetate and hexane. The structures of synthetic stilbenes are presented in Fig. 1b. Detailed synthetic methods and results of instrumental analyses are provided in additional file.

\section{Antiproliferative activity and antioxidant activity of synthetic stilbenes}

Antiproliferative activity of title compounds (1-14) was evaluated with sulforhodamine B (SRB) assay, while antioxidant activity (ABTS and DPPH assays) was tested using literature methods [13].

\section{Molecular property calculation and docking studies}

Ligand-receptor docking study was carried out with CA-4 and derivatives using SwissDock $[14,15]$. Energyminimized ligand structures and its partial charges were calculated with HyperChem ver. 8.0 (Hypercube Inc.). The crystal structure of $\beta$-tubulin complexed with CA-4 (accession code: 5LYJ) was obtained from RCSB Protein Data Bank (PDB, https://www.rcsb.org). Heteroatoms (e.g., CA-4, water, GTPs, etc.) and $\alpha$-tubulin subunit were removed. Polar hydrogens were added to the $\beta$-subunit using Molecular Discovery Studio ver. 3.0 (Accelrys Software Inc.). Ligand was docked to the $\beta$-subunit in 5LYJ with default option. Docking results were visualized with Chimera or Molecular Discovery Studio [16]. Molecular surface area (square angstrom, SA) was estimated from the energy minimized structure using HyperChem. 


\section{Results and discussion}

Among the four cancer cell lines, HT-29, human colon colorectal adenocarcinoma cells were strongly inhibited by most synthetic stilbenes $\left(\mathrm{IC}_{50} \mathrm{~s}=0.009-1.9 \mu \mathrm{M}\right)$, while the stilbenes showed a moderate antiproliferative activity on HeLa cells. However, the inhibitory activity of stilbenes was limited in SK-OV-3 and A549 cell lines (Table 1). In comparison with cancer cell lines, normal cells (canine kidney cell, MDCK and human keratinocyte, $\mathrm{HaCaT}$ ) were resistant to stilbenes-mediated cell growth inhibition. In general, cis-isomers gave much stronger antiproliferative activities over their transisomers. For example, $\mathrm{IC}_{50}$ of analogue 2 was 10 fold less than that of its trans-isomer (9).Among derivatives, CA-4 (1) and its 4-methoxy analogue (2) were the most potent derivatives (e.g., $\mathrm{IC}_{50 \mathrm{~s}}$ for HT-29, 9 and $20 \mathrm{nM}$, respectively). Polymethylenedioxy analogues of 2 (4-7) showed reduced activities over 2 . Methylenedioxy stilbene (4) was the least active analogue. Compounds 5-6 with bulkier substituents showed enhanced activities against some cancer cell lines. For example, $\mathbf{5}$ was almost equally potent to 2 against $\mathrm{HeLa}$ cells $\left(\mathrm{IC}_{50}, 1.19\right.$ and $3.59 \mu \mathrm{M}$ for $\mathbf{2}$ and 5, respectively). In case of A549 cells, propylenedioxy compound (6) was the most potent analogue among all test compounds. However, the decreased activity of 7 indicated that there are optimum values of steric bulkiness of the substituents. In general, cancer cell lines showed larger variability of cytotoxicity than those of normal cells (Table 1). For example, there were approximately 200-fold differences between analogues against HT-29 cells (9 $\mathrm{nM}$ and $1.907 \mu \mathrm{M}$ for $\mathbf{1}$ and 12, respectively) while only three-fold differences were found against $\mathrm{HaCaT}$ cells $(41.07 \mu \mathrm{M}$ and $135.57 \mu \mathrm{M}$ for 8 and 14, respectively). 4-Trifluoromethoxy stilbene (3) showed an interesting response. Although the SAs of 2 and 3 were slightly different (3 was 1.5\% larger than 2 ), 3 was approximately 100 -fold less active than its closely related analogue $\mathbf{2}$ (Tables 1, 2).

Ligand-protein docking simulation is frequently used in drug development. Reliability of the predictive model is strongly dependent on accuracies of protein structures. There are numerous X-ray crystallographic studies of anti-microtubule drugs [17-20]. Results have proven that the morphology of binding pockets can be changed by ligand. A recent study on CA-4 has shown detailed features of its binding site on microtubule [11]. In brief, the shape was closely related to that of classical ligand, colchicine. For example, trimethoxyphenyl ring of CA-4 (ring A) give strong interaction with cysteine 241 (deep binding pocket), while ring $\mathrm{B}$ of CA-4 make hydrogen bonds with tyrosine in $\alpha$-tubulin ( $\alpha \mathrm{T} 179)$ and lysine (K352) (shallow binding trench). However, notable differences have also been observed, including the depth of binding pocket and the amino acid residues in closecontact with CA-4. According to crystallographic study, additional hydrophobic interaction between ligands and $\beta$-tubulin unit was found-namely interaction between CA-4 and alanine/leucine residues [11]. In the present study, molecular docking studies were performed using crystallographic coordinates of CA-4 and microtubule

Table 1 Antiproliferative activity of combretastatin A-4 and polymethylenedioxy analogues on various tumor cell lines and normal cells and antioxidant activities

\begin{tabular}{|c|c|c|c|c|c|c|c|c|}
\hline \multirow[t]{2}{*}{ ID } & \multicolumn{6}{|c|}{$\begin{array}{l}\text { Antiproliferative activity } \\
I C_{50}(\mu M \pm S D)\end{array}$} & \multicolumn{2}{|c|}{$\begin{array}{l}\text { Antioxidant activity } \\
\mathrm{IC}_{50}(\mathrm{mg} / \mathrm{mL} \pm \mathrm{SD})^{\mathrm{a}}\end{array}$} \\
\hline & HeLa & SK-OV-3 & A549 & HT-29 & $\mathrm{HaCaT}$ & MDCK & DPPH & ABTS \\
\hline 1 & $7.78 \pm 0.50$ & $20.25 \pm 2.00$ & $269.11 \pm 6.46$ & $0.009 \pm 0.000$ & $55.09 \pm 0.48$ & $40.31 \pm 0.26$ & $4.65 \pm 0.02$ & $1.56 \pm 0.02$ \\
\hline 2 & $1.19 \pm 0.25$ & $1.66 \pm 0.18$ & $11.26 \pm 0.16$ & $0.020 \pm 0.003$ & $60.83 \pm 1.14$ & $50.1 \pm 0.34$ & $72.71 \pm 3.02$ & $99.28 \pm 2.75$ \\
\hline 3 & $17.96 \pm 2.23$ & $480.99 \pm 5.76$ & $190.46 \pm 0.81$ & $0.440 \pm 0.081$ & $53.98 \pm 0.49$ & $120.07 \pm 2.14$ & $90.79 \pm 2.22$ & $94.08 \pm 0.67$ \\
\hline 4 & $6.44 \pm 0.64$ & $333.35 \pm 6.95$ & $173.18 \pm 1.08$ & $0.104 \pm 0.030$ & $68.42 \pm 3.68$ & $100.47 \pm 1.25$ & $33.19 \pm 0.26$ & $99.48 \pm 0.15$ \\
\hline 5 & $3.59 \pm 0.30$ & $162.50 \pm 1.72$ & $98.02 \pm 2.38$ & $0.090 \pm 0.001$ & $57.5 \pm 3.36$ & $98.59 \pm 1.80$ & $30.08 \pm 1.12$ & $99.66 \pm 0.82$ \\
\hline 6 & $5.35 \pm 0.26$ & $50.30 \pm 0.18$ & $9.29 \pm 0.35$ & $0.482 \pm 0.021$ & $56.04 \pm 0.11$ & $111.10 \pm 1.58$ & $67.30 \pm 2.64$ & $78.06 \pm 1.27$ \\
\hline 7 & $130.86 \pm 3.01$ & $213.55 \pm 5.38$ & $122.37 \pm 0.25$ & $0.110 \pm 0.001$ & $84.40 \pm 0.08$ & $233.45 \pm 2.02$ & $66.30 \pm 0.25$ & $98.49 \pm 1.94$ \\
\hline 8 & $52.18 \pm 1.00$ & $125.31 \pm 0.63$ & $261.52 \pm 6.59$ & $0.006 \pm 0.000$ & $41.07 \pm 3.14$ & $66.84 \pm 1.02$ & $5.71 \pm 0.05$ & $2.79 \pm 0.01$ \\
\hline 9 & $26.88 \pm .43$ & $147.67 \pm 0.16$ & $164.5 \pm 8.70$ & $0.280 \pm 0.030$ & $107.83 \pm 0.80$ & $101.53 \pm 1.16$ & $89.81 \pm 0.73$ & $98.18 \pm 0.96$ \\
\hline 10 & $9.73 \pm 0.71$ & $460.91 \pm 12.1$ & $202.01 \pm 2.19$ & $0.479 \pm 0.106$ & $135.28 \pm 4.39$ & $151.27 \pm 0.75$ & $34.78 \pm 0.75$ & $84.11 \pm 0.35$ \\
\hline 11 & $8.55 \pm 0.67$ & $165.43 \pm 0.54$ & $239.46 \pm 9.31$ & $0.047 \pm 0.010$ & $131.68 \pm 2.53$ & $130.17 \pm 2.67$ & $64.12 \pm 0.68$ & $93.34 \pm 0.94$ \\
\hline 12 & $191.63 \pm 2.47$ & $136.54 \pm 1.46$ & $204.97 \pm 5.75$ & $1.907 \pm 0.013$ & $102.34 \pm 2.06$ & $375.61 \pm 6.90$ & $64.18 \pm 2.18$ & $88.41 \pm 1.04$ \\
\hline 13 & $89.52 \pm 1.34$ & $121.47 \pm 0.52$ & $110.61 \pm 0.17$ & $0.433 \pm 0.117$ & $71.75 \pm 1.12$ & $222.76 \pm 1.55$ & $54.80 \pm 3.18$ & $83.45 \pm 1.19$ \\
\hline 14 & $200.65 \pm 3.22$ & $288.13 \pm 4.22$ & $332.12 \pm 9.48$ & $1.218 \pm 0.020$ & $135.57 \pm 1.68$ & $1540.3 \pm 9.98$ & $70.62 \pm 3.31$ & $96.93 \pm 3.53$ \\
\hline
\end{tabular}

${ }^{a} \mathrm{IC}_{50}$ s of reference compound (ascorbic acid) for DPPH and ABTS assay were $8.43 \pm 0.21$ and $22.41 \pm 0.24 \mathrm{mg} / \mathrm{mL}$, respectively 
Table 2 Binding free energies and surface area of combretastatin A-4 and polymethylenedioxy analogues of combretastatin A-2

\begin{tabular}{|c|c|c|c|c|c|}
\hline Compounds & Free energy ${ }^{b}$ & Surface area & Compounds & Free energy & Surface area \\
\hline $1(Z)^{a}$ & -8.9149 & 562.98 & $8(E)$ & -8.2185 & 574.25 \\
\hline $2(Z)$ & -8.5054 & 555.73 & $9(\mathrm{E})$ & -7.9875 & 567.55 \\
\hline $3(Z)$ & -8.0018 & 564.28 & $10(E)$ & -7.8679 & 585.66 \\
\hline $4(Z)$ & -8.06606 & 500.69 & $11(\mathrm{E})$ & -7.8868 & 522.57 \\
\hline $5(Z)$ & -8.1496 & 539.12 & $12(\mathrm{E})$ & -7.7385 & 546.08 \\
\hline $6(Z)$ & -8.0908 & 561.26 & $13(E)$ & -7.6235 & 570.91 \\
\hline 7(Z) & -8.2103 & 585.55 & $14(E)$ & -7.5486 & 589.23 \\
\hline
\end{tabular}

a The geometry of stilbenes were described as (Z) for cis-isomers and (E) for trans-isomers

b Binding free energy $\Delta \mathrm{G}$ in $\mathrm{kcal} / \mathrm{mol}$

c Surface area (square angstrom/mol)

(5LYJ). First of all, binding conformations of CA-4 were predicted and compared with experimental data (Fig. 2a). Results indicated that the predicted binding conformation well coincided with crystallographic data-rings A and $\mathrm{B}$ and its substituents are located at the same positions. With this in hand, binding energies and other molecular properties were evaluated (Table 2). According to simulations, binding conformations of 2-5 closely resembled those of CA-4. Ring A of stilbenes was positioned into a deep binding pocket while ring $\mathrm{B}$ (4-methoxyphenyl) was located at a shallow trench (Fig. $2 \mathrm{~b}$ and Additional file 1: Fig. S2). Gaspari et al. pointed out that CA-4- $\beta$-tublin complex is stabilized by hydrophobic interaction and hydrogen bond, among which the interaction between methoxy groups of ring $\mathrm{A}$ and cysteine 241 (C241) is one of the most critical determinants. Structure-activity relationships (SARs) study with CA-4 analogues indicated that steric fitness of ring A substituents is an important factors in stilbene-tubulin-binding procedures [6]. CA-4 analogues with smaller steric volume (e.g., trimethyl and trifluoro derivatives) showed reduced cytotoxicity and tubulin assembly inhibition, while those with bulky substituents (e.g., triethoxy) also gave limited bioactivity [6]. The results indicated that there are optimum steric properties (e.g., volume or surface) of stilbene derivatives. Steric volumes of $\mathbf{4}$ and $\mathbf{5}$ are much smaller than CA-4 (Table 2). Thus the interaction with hydrophobic amino acids may be reduced and resulted in the loss of antiproliferative activity of $\mathbf{4}$ and 5. Interestingly, preferred conformations of compounds 6 and 7 were quite different from others. Ring A of 6 and 7 was placed on a shallow pocket while the same rings of CA-4 and 2-5 are located in a deep pocket (Fig. 2a-c and Additional file 1: Fig. S2). According to experimental study $[11,17,18]$, trimethoxyphenyl unit of CA-4 is bound to deeply buried hydrophobic pocket comprised of lipophilic residues (e.g., alanine, cysteine, isoleucine, leucine, and valine). These residues further stabilize the ligand-tubulin complex through hydrophobic interaction. The shallow binding pocket around ring B is mainly comprised of polar amino acids (asparagine and lysine), where hydrogen bond became important for proper binding. Low bioactivity of 7 may result from steric incompatibility of ring $\mathrm{A}$ on this polar binding pocket. Additionally, limited hydrophobic interaction between ring $B$ and deep pocket may also reduce the activity. In comparison with 7 , stilbene 6 showed stronger cytotoxicity over 7 , indicating that the shallow binding pocket cannot accommodate ligands larger than propylenedioxy analogue (6). In general, binding free energies $(\Delta \mathrm{G})$ of trans-isomers were far smaller than those of cis-isomers (Table 2). As mentioned above, the interaction between ring $\mathrm{A}$ and deep binding pocket is very important. However, simulation studies showed that ring A of trans-stilbenes, except 11, was positioned at the shallow pocket, rather than the deeper binding sites (Fig. 2d, e, and Additional file 1: Fig. S3). As in the case of 7 , such binding conformation reduced the interaction and consequently the binding affinity. Molecular simulation with stilbene $\mathbf{3}$ showed the importance of electrostatic properties of ring B (Fig. 3). The shallow binding pocket in experimental structure showed slightly negative charges originated from asparagine and lysine. According to semi-empirical calculation of CA-4 and 3, partial positive charge (0.052) was observed in the methoxy hydrogen of ring B (CA-4), while strongly negative charge was predicted on the fluorine atoms in 3 (-0.143) (Fig. 3b, c). From the results, it can be suggested that there are repulsive interaction between 3 and its binding pocket. In general, predicted binding free energy $(\Delta G)$ of CA- 4 and cis-isomers showed strong correlation with antiproliferative activity. However, some trans-stilbenes with low $\Delta \mathrm{G}$ showed stronger cytotoxicity than cis-isomers (e.g., 3 and 10) (Tables 1, 2). It is noteworthy that cis-trans isomerization of stilbene has been 

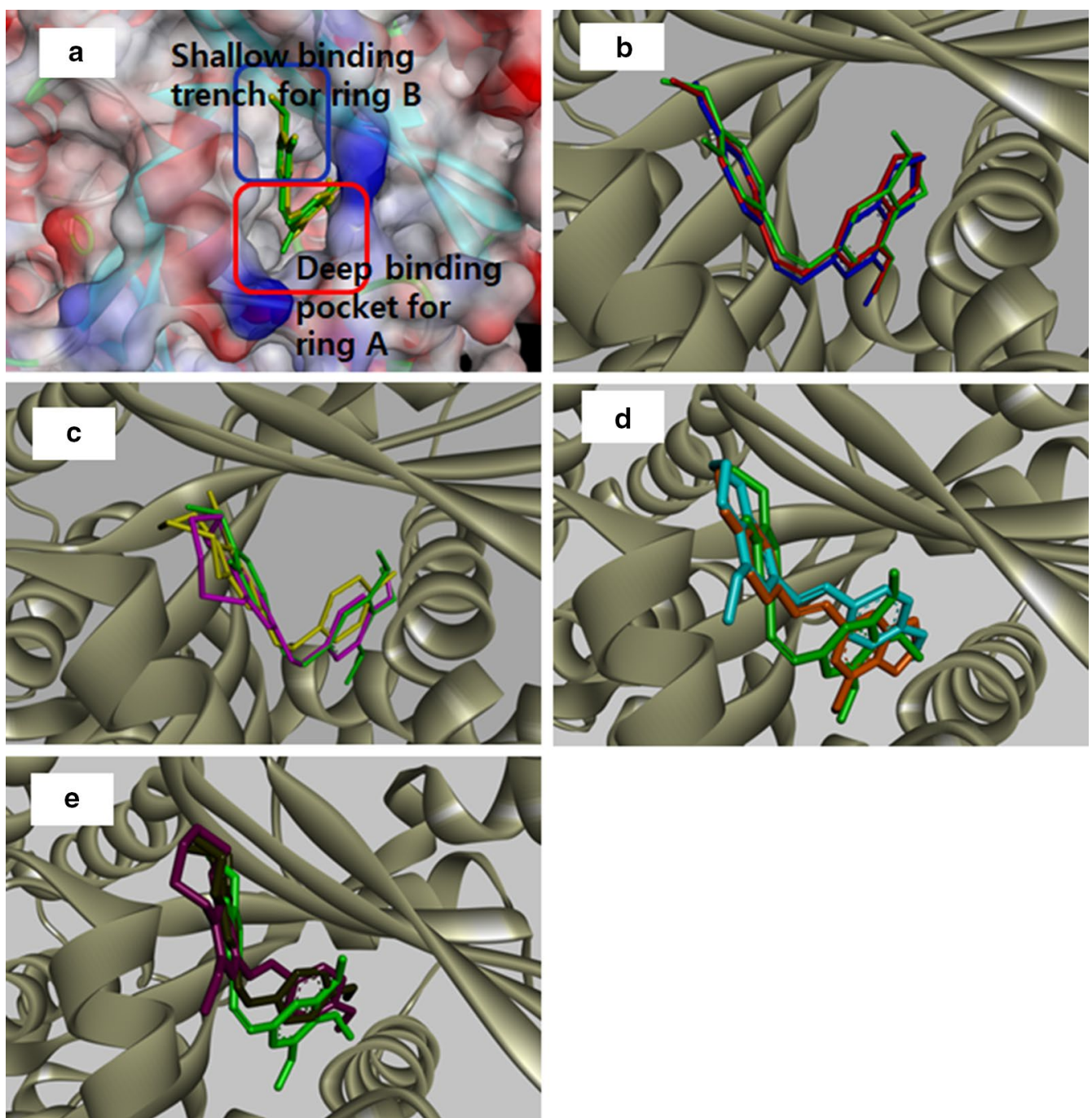

Fig. 2 Predicted binding conformations of CA-4 (yellow), overlaid on surface area of crystallographic structures of CA-4 (green) and $\beta$-tubulin with description of binding pocket (a), and polymethylenedioxy compounds $\mathbf{4}$ (red) and $\mathbf{5}$ (blue) (b), $\mathbf{6}$ (yellow) and $\mathbf{7}$ (pink) (c), $1 \mathbf{1}$ (brown) and $\mathbf{1 2}$ (pale blue) (d), and $\mathbf{1 3}$ (dark green) and $\mathbf{1 4}$ (violet) (e) on $\beta$-tubulin overlaid on crystallographic structure of CA-4 in 5LYJ (green)

found in human colon cancer study [21]. Although freeenergy barriers between cis- and trans-isomers are quite high, molecular dynamics study has suggested possibilities of such isomerization [11]. According to an in vivo study with mouse, isomerization is clearly observed and the extent is variable, depending on substituents [21]. Discrepancy between cytotoxicity and $\Delta G$-based prediction may in part result from such metabolic transformation. However, detailed studies are required to confirm isomerization.

Resveratrol, a natural stilbene is well-known for its antioxidant activities [22]. It has to be mentioned that fully methylated resveratrol analogue has also strong hydroxyl radical scavenging activity and protective effects against radical-mediated DNA damage [23]. The findings indicate that synthetic stilbenes (1-14) may also give similar activity. Antioxidant activities of stilbenes (1-14) were evaluated by DPPH and ABTS methods (Table 1). CA-4 was found to be a strong antioxidant while other analogues showed marginal activities in ABTS and DPPH assays. The results well coincided with those of other resveratrol analogues $[24,25]$. Multiple hydroxy substituents are common features of natural antioxidants, including stilbenes and flavonoids [24-26]. According to theoretical study, the phenolic hydroxy group is an important determinant for radical scavengers (e.g., resveratrol) since the functional group can be a good source of hydride (an 

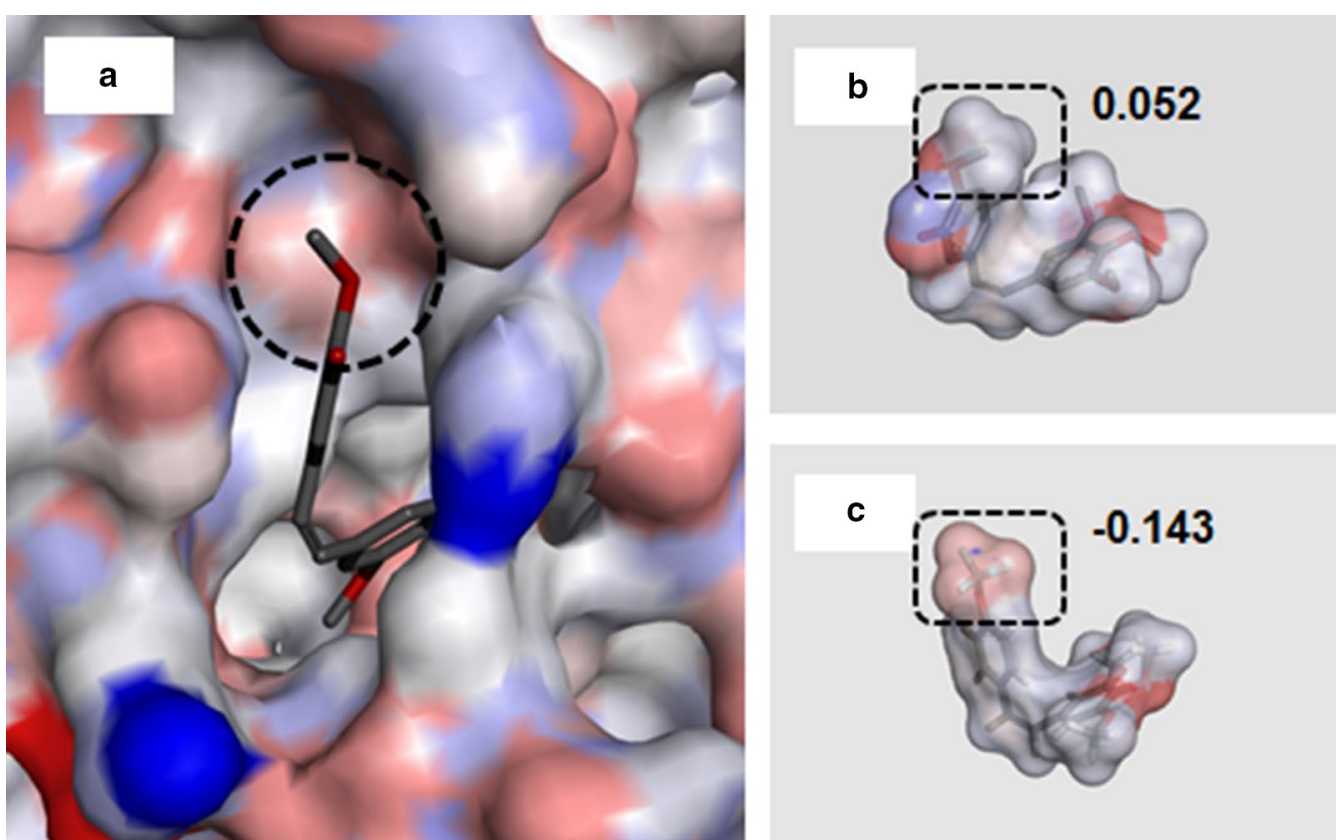

Fig. 3 Atomic charges of surface area of binding pocket of $\beta$-tubulin in 5LYJ (a), and those of CA-4 (b) and stilbene $\mathbf{3}$ (c). Blue color for positive and red for negative charges. Dotted circle and rectangles are for 4-methoxy (or 4-trifluoromethoxy substituents) Values in insert B and C are partial charges of hydrogen or fluorine atoms in CA-4 and $\mathbf{3}$

efficient reducing reagent in radical removal), while the methoxy group cannot provide the same reductant [27].

In summary, polymethylenedioxy analogues of CA-2 were prepared and their antiproliferative activity was evaluated. Their bioactivities were explained by molecular docking studies. Results indicated that binding conformations of title compounds were highly dependent on steric properties of ring A substituents. Electrostatic complementarity between ring $\mathrm{B}$ and tubulin was also an important factor that determines the cytotoxicity.

\section{Additional file}

Additional file 1. In the additional file, the following data were included analytical results of synthetic stilbenes, figures of ligand-protein docking study, and details of antioxidant activity of synthetic stilbenes.

\section{Authors' contributions}

Y-SK and YSK carried out synthesis, bioassay, and molecular modelling. EG and BMM contributed to detailed bioassay. S-HJ help the synthetic method development. All authors read and approved the final manuscript.

\section{Author details}

${ }^{1}$ Department of Crop Science, Konkuk University, 120 Neungdong-ro, Gwangjin-gu, Seoul 05029, Korea. ${ }^{2}$ Department of Forestry and Landscape Architecture, Konkuk University, 120 Neungdong-ro, Gwangjin-gu, Seoul 05029, Korea. ${ }^{3}$ Department of Food Science and Biotechnology, Dongguk University, Seoul 410-820, Korea.

\section{Acknowledgements}

This research was supported by BrainKorea 21 Grants.

\section{Competing interests}

The authors declare that they have no competing interests.

\section{Publisher's Note}

Springer Nature remains neutral with regard to jurisdictional claims in published maps and institutional affiliations.

Received: 27 March 2019 Accepted: 13 April 2019

Published online: 30 April 2019

\section{References}

1. Lawrence NJ, Hepworth LA, Rennison D, McGown AT, Hadfield JA (2003) Synthesis and anticancer activity of fluorinated analogues of combretastatin A-4. J Fluorine Chem 123:101-108

2. Maya ABS, Pérez-Melero C, Mateo C, Alonso D, Fernández UL, Gajate C, Mollinedo F, Peláez R, Caballero E, Medarde M (2005) Further naphthylcombretastatins. An investigation on the role of the naphthalene moiety. J Med Chem 48:556-568

3. Pettit GR, Rhodes MR, Herald DL, Hamel E, Schmidt JM, Pettit RK (2005) Antineoplastic agents. 445. Synthesis and evaluation of structural modifications of (Z)- and (E)-combretastatin A-4. J Med Chem 48:4087-4099

4. Simoni $D$, Invidiata FP, Eleopra M, Marchetti P, Rondanin R, Baruchello R, Grisolia G, Tripathi A, Kellogg GE, Durrant D, Lee RM (2009) Design, synthesis and biological evaluation of novel stilbene-based antitumor agents. Bioorg Med Chem 17:512-522

5. Pettit GR, Thornhill A, Melody N, Knight JC (2009) Antineoplastic agents. 578. Synthesis of stilstatins 1 and 2 and their water-soluble prodrugs. J Nat Prod 72:380-388

6. Gaukroger K, Hadfield JA, Lawrence NJ, Nolan S, McGown AT (2003) Structural requirements for the interaction of combretastatins with 
tubulin: how important is the trimethoxy unit? Org Biomol Chem 1:3033-3037

7. Liou JP, Chang YL, Kuo FM, Chang CW, Tseng HY, Wang CC, Yang YN, Chang JY, Lee SJ, Hsieh HP (2004) Concise synthesis and structure-activity relationships of combretastatin A-4 analogues, 1-aroylindoles and 3-aroylindoles, as novel classes of potent antitubulin agents. J Med Chem 47:4247-4257

8. Marrelli M, Conforti F, Statti AG, Cachet X, Michel S, Tillequin F, Menichini F (2011) Biological potential and structure-activity relationships of most recently developed vascular disrupting agents: an overview of new derivatives of natural combretastatin A-4. Curr Med Chem 18:3035-3081

9. Arthuis M, Pontikis R, Chabot GG, Seguin J, Quentin L, Bourg S, MorinAllory L, Florent JC (2011) Synthesis and structure-activity relationships of constrained heterocyclic analogues of combretastatin A4. ChemMedChem 6:1693-1705

10. Wang L, Woods KW, Li Q, Barr KJ, McCroskey RW, Hannick SM, Gherke L, Credo RB, Hui YH, Marsh K, Warner R, Lee JY, Zielinski-Mozng N, Frost D, Rosenberg SH, Sham HL (2002) Potent, orally active heterocycle-based combretastatin A-4 analogues: synthesis, structure-activity relationship, pharmacokinetics, and in vivo antitumor activity evaluation. J Med Chem 45:1697-1711

11. Gaspari R, Prota AE, Bargsten K, Cavalli A, Steinmetz MO (2017) Structural basis of cis- and trans-combretastatin binding to tubulin. Chem 2:102-113

12. Semenov VV, Kiselyov AS, Titov IY, Sagamanova IK, I kizalp NN, Chernysheva NB, Tsyganov DV, Konyushkin LD, Firgang SI, Semenov RV, Karmanova IB, Raihstat MM, Semenova MN (2010) Synthesis of antimitotic polyalkoxyphenyl derivatives of combretastatin using plant allylpolyalkoxybenzenes. J Nat Prod 73:1796-1802

13. Mistry BM, Patel RV, Keum YS, Kim DH (2016) Synthesis of 9-O-3-(1-piperazinyl/morpholinyl/piperidinyl)pentyl-berberines as potential antioxidant and cytotoxic agents. Anticancer Agents Med Chem 16:713-721

14. Grosdidier A, Zoete V, Michielin O (2011) SwissDock, a protein-small molecule docking web service based on EADock DSS. Nucleic Acids Res 39:W270-W277

15. Grosdidier A, Zoete V, Michielin O (2011) Fast docking using the CHARMM force field with EADock DSS. J Comput Chem 32:2149-2159

16. Pettersen EF, Goddard TD, Huang CC, Couch GS, Greenblatt DM, Meng EC, Ferrin TE (2004) UCSF Chimera-a visualization system for exploratory research and analysis. J Comput Chem 25:1605-1612
17. Ravelli RB, Gigant B, Curmi PA, Jourdain I, Lachkar S, Sobel A, Knossow M (2004) Insight into tubulin regulation from a complex with colchicine and a stathmin-like domain. Nature 428:198-202

18. Gigant B, Wang C, Ravelli RB, Roussi F, Steinmetz MO, Curmi PA, Sobel A, Knossow M (2005) Structural basis for the regulation of tubulin by vinblastine. Nature 435:519-522

19. Sharma A, Saez-Calvo G, Olieric N, de Asis Balaguer F, Barasoain I, Lamberth C, Diaz JF, Steinmetz MO (2017) Quinolin-6-yloxyacetamides are microtubule destabilizing agents that bind to the colchicine site of tubulin. Int J Mol Sci 18:1336

20. Yang JH, Yan W, Yu YM, Wang YX, Yang T, Xue LL, Yuan X, Long CF, Liu ZW, Chen XX, Hu MS, Zheng L, Qiu Q, Pei HY, Li D, Wang F, Bai P, Wen JL, Ye HY, Chen $\sqcup$ (2018) The compound millepachine and its derivatives inhibit tubulin polymerization by irreversibly binding to the colchicine-binding site in beta-tubulin. J Biol Chem 293:9461-9472

21. Paul S, Mizuno CS, Lee HJ, Zheng X, Chajkowisk S, Rimoldi JM, Conney A, Suh NJ, Rimando AM (2010) In vitro and in vivo studies on stilbene analogs as potential treatment agents for colon cancer. Eur J Med Chem 45:3702-3708

22. Miura T, Muraoka S, Ikeda N, Watanabe M, Fujimoto Y (2000) Antioxidative and prooxidative action of stilbene derivatives. Pharmacol Toxicol 86:203-208

23. Rossi M, Caruso F, Antonioletti R, Viglianti A, Traversi G, Leone S, Basso E, Cozzi R (2013) Scavenging of hydroxyl radical by resveratrol and related natural stilbenes after hydrogen peroxide attack on DNA. Chem Biol Interact 206:175-185

24. Murias M, Jäger W, Handler N, Erker T, Horvath Z, Szekeres T, Nohl H, Gille $L$ (2005) Antioxidant, prooxidant and cytotoxic activity of hydroxylated resveratrol analogues: structure-activity relationship. Biochem Pharmacol 69:903-912

25. Hasiah AH, Ghazali AR, Weber JF, Velu S, Thomas NF, Inayat Hussain SH (2011) Cytotoxic and antioxidant effects of methoxylated stilbene analogues on HepG2 hepatoma and Chang liver cells: implications for structure activity relationship. Hum Exp Toxicol 30:138-144

26. Hudson BJF, Lewis II (1983) Polyhydroxy flavonoid antioxidants for edible oils. Structural criteria for activity. Food Chem 10:47-55

27. Mikulski D, Gorniak R, Molski M (2010) A theoretical study of the structure-radical scavenging activity of trans-resveratrol analogues and cis-resveratrol in gas phase and water environment. Eur J Med Chem 45:1015-1027

\section{Submit your manuscript to a SpringerOpen ${ }^{\circ}$ journal and benefit from:}

- Convenient online submission

- Rigorous peer review

- Open access: articles freely available online

- High visibility within the field

- Retaining the copyright to your article

Submit your next manuscript at $\boldsymbol{\nabla}$ springeropen.com 